\title{
0 Impacto do Tempo de Pendência das Patentes na Trajetória de Crescimento: Uma Análise com Base no Modelo Schumpeteriano de Crescimento Endógeno com Avanço de Qualidade
}

\author{
Fábio Rodrigues de Moura*, Nelson Leitão Paes ${ }^{\dagger}$, Tácito Augusto \\ Farias $^{\ddagger}$
}

Conteúdo: 1. Introdução; 2. O Modelo Econômico; 3. Calibração e Análise dos Resultados; 4. Considerações Finais.

Palavras-chave: Patentes, Tempo de Pendência, Crescimento Endógeno, Modelo Schumpeteriano.

Códigos JEL: 031034043.

O objetivo deste trabalho é analisar o impacto do tempo de pendência das patentes sobre a trajetória de crescimento equilibrado da economia. Trabalhamos com a hipótese de que o tempo de pendência representa um período de incerteza para os agentes inovativos, o que afeta os esforços de P\&D. Para operacionalizar nossas hipóteses utilizamos o modelo schumpeteriano de crescimento endógeno com avanço de qualidade, baseado em Grossman e Helpman (1991a,b) e Aghion e Howitt (1992). Nossos resultados mostram que o tempo de pendência tem um impacto negativo sobre o crescimento e o bem-estar da economia, de forma que períodos mais longos de espera pela decisão da patente geram uma maior perda em termos de crescimento. Isto sugere a necessidade de políticas que visem a reduzir, de forma eficiente, o tempo de exame das patentes.

This study aims to analyze the impact of the patent pendency time on the Balanced Growth Path (BGP). We assume that during the pendency time the innovative agents face an uncertainty period, which affects the RED efforts. To operate our assumptions we use the schumpeterian endogenous

\footnotetext{
* Doutorando em Economia Aplicada pela Universidade de São Paulo (ESALQ/USP). E-mail: fabirosmash@yahoo.com.br

†Professor do Programa de Pós-Graduação em Economia (PIMES) da Universidade Federal de Pernambuco (UFPE). E-mail: nlpaes@gmail.com

${ }^{\ddagger}$ Professor do Departamento de Economia da Universidade Federal de Sergipe (UFS). E-mail: tacitoaugusto@yahoo.com. br
} 
growth model based in Grossman e Helpman (1991a,b) and Aghion e Howitt (1992). Our results show that the pendency time has a negative impact on growth and welfare, so that a longer delay for the patent decision increases the growth loss. This suggests the implementation of policies to reduce efficiently the patent examination time.

\section{INTRODUÇÃO}

A literatura sobre crescimento econômico amplamente reconhece que o fluxo de inovações tecnológicas é uma das principais fontes de crescimento persistente no longo prazo. O progresso tecnológico endógeno é gerado através da aplicação do conhecimento, dado este ser um bem diferente dos demais devido a sua capacidade de apresentar produtividade marginal não decrescente Romer (1986). Entretanto, os avanços tecnológicos estão fortemente ligados aos incentivos econômicos. Conforme atestam Grossman e Helpman (1994), em geral os indivíduos investem recursos na produção de novas tecnologias quando visualizam a oportunidade de obter um retorno significativo com suas criações. A lucratividade oriunda de uma invenção, por sua vez, depende do ambiente institucional, legal e econômico da sociedade. Juntos, estes ambientes determinam o chamado sistema de propriedade intelectual, que afeta fortemente o ritmo e a direção do progresso tecnológico.

A patente é o principal mecanismo que garante os direitos de propriedade intelectual a um agente inovador. Uma patente confere ao seu detentor um direito de propriedade sobre um produto ou processo durante um determinado número de anos, traduzindo-se em um instrumento de recompensa pela atividade inventiva. A proteção através de patentes justifica-se, dentre outros motivos, pelo fato de que os custos da descoberta são bem mais altos se comparados aos custos da imitação (Helpman, 1993). Se uma criação puder ser rapidamente imitada, o retorno econômico do inventor é reduzido, o que gera um desincentivo ao investimento em pesquisa. A patente permite ao inventor, na forma de um poder de monopólio, se apropriar de um benefício econômico exclusivo, em virtude de sua contribuição ao estoque tecnológico da sociedade, o que contribui para evitar sub-investimentos na atividade inventiva.

A literatura recente que analisa o crescimento endógeno foi desenvolvida supondo-se um ambiente institucional onde os direitos de propriedade intelectual são bem estabelecidos. Em Romer (1990), Grossman e Helpman (1991a,b), Aghion e Howitt (1992), Kortum (1997), Aghion et alii (2001) e Aghion et alii (2005) há uma forte conexão entre a atividade inventiva e o estabelecimento do poder de monopólio. Nestes modelos os novos bens e as novas tecnologias são introduzidos no mercado graças à busca dos inventores por oportunidades de lucro. Tais oportunidades surgem ao se obter uma patente que garante o direito de monopólio sobre as invenções.

Entretanto, os modelos de crescimento costumam abstrair um importante aspecto do sistema de propriedade intelectual: o tempo de espera pela decisão da patente. Geralmente trabalha-se com a hipótese de que uma patente é instantaneamente concedida no momento em que um novo produto é criado, o que permite aos inventores extrair os lucros do monopólio a partir do instante em que desenvolvem com sucesso um novo design.

Na prática, o inventor que deseja receber uma patente pela sua criação deve requisitá-la junto a um escritório de patentes, instituição responsável por analisar e conceder uma patente ao produto caso cumpra com os pré-requisitos legais de inovação e atividade inventiva. O processo de exame do pedido de patente consome um período de tempo, denominado tempo de pendência, que engloba desde o depósito do pedido até a decisão final, e que pode vir a ser bastante considerável a depender da operacionalização e estrutura do escritório de patentes em cada país. Ao final do ano de 2011, por exemplo, o United States Patent and Trademark Office (USPTO), o escritório de patentes dos Estados Unidos, decidia sobre os pedidos de patente em um tempo médio de 2,8 anos. Já o Instituto Nacional de Propriedade Industrial (INPI), órgão responsável pela concessão das patentes no Brasil, divulgou no início de 2012 que o tempo médio de espera foi reduzido de 8,3 anos em 2010 para 5,4 anos em 2011. 
Isto representou, em apenas um ano, uma redução significativa de $35 \%$ no tempo médio de espera pela decisão das patentes no Brasil. Ainda assim, a diferença entre o tempo médio de pendência no Brasil e nos Estados Unidos era de quase $93 \%$ na época.

O tempo gasto pelos escritórios de patentes para analisar e decidir quanto à concessão do direito legal de monopólio pode influenciar significativamente no montante destinado e no tipo de pesquisa realizada pelos agentes econômicos. Primeiramente, cada ano adicional de espera reduz o tempo de vida efetivo da patente, tendo em vista que esta é um título de propriedade temporária e, em geral, o tempo de duração da patente é contado a partir da data de depósito do pedido e não da data de concessão. Ademais, durante o tempo de espera pelo resultado da patente o inventor tem apenas uma expectativa de direito de monopólio. Este direito somente se confirma no momento da decisão, caso o escritório de patentes entenda que o produto atende aos pré-requisitos legais de patentabilidade. E embora a legislação que regulamenta a concessão de patentes permita ao inventor requisitar indenização por perdas e danos caso o seu produto venha a ser imitado durante o período de pendência, esse direito só pode ser exercido se a patente vier de fato a ser concedida. Em países onde o tempo de espera pela decisão da patente é curto essa proteção pode se mostrar bastante efetiva. Por outro lado, em países como o Brasil, onde o tempo de espera pela decisão da patente ainda é relativamente longo, há um aumento no nível de incerteza enfrentado pelo agentes criadores de tecnologia.

Há dois potenciais riscos envolvidos caso um agente deseje fornecer a sua tecnologia ao mercado antes de se obter uma patente. Uma empresa pode pagar royalties ao inventor pelo uso de um produto que, após o período de pendência, pode vir a ser constatado como já pertencente ao domínio público, situação na qual a patente é negada e o direito de exclusividade não se confirma. Há também o risco de um agente concorrente não aceitar a expectativa de direito e copiar o produto durante o tempo de exame. Neste caso, o agente poderá ser processado por perdas e danos se a patente vier a ser concedida. Mas se o tempo de julgamento da patente for longo a incerteza de todos os agentes envolvidos se eleva. Por conseguinte, isto torna pouco atrativo o aproveitamento da tecnologia candidata à patente. A incerteza sobre os direitos de propriedade pode forçar os inventores a reter a sua tecnologia, em termos de produção e licenciamento, enquanto o resultado da patente não for conhecido.

Em particular, há dois importantes estudos que buscam estimar o impacto do tempo de pendência sobre o valor da patente. Um deles, realizado pela consultoria London Economics a pedido do escritório de patentes do Reino Unido, estimou que um ano adicional de pendência gera um custo de 6 bilhões de libras por ano na forma de perda de inovações (London Economics, 2010). Este custo foi estimado com base nos dados disponíveis para os escritórios dos Estados Unidos, da Europa e do Japão, e sob a hipótese de que um aumento do tempo de espera reduz o período no qual o agente pode se beneficiar da proteção patentária, o que consequentemente reduz o valor da patente e a quantidade de pedidos aplicados. $O$ estudo conclui que o custo do aumento da pendência é significativo e acaba por reduzir os incentivos à inovação e o bem-estar.

Outro estudo realizado pelo USPTO buscou estimar os ganhos monetários advindos de uma redução no tempo médio de pendência do órgão, que seria possível através de uma mudança na política de encargos cobrados sobre as patentes. O novo esquema proposto prevê um decréscimo de 12 meses no tempo médio de pendência ao longo do período 2013-2017, o que resultaria em um ganho total para os requisitantes domésticos de patentes e para a sociedade de aproximadamente 7,7 bilhões de dólares ao fim de 2017 (UNITED STATES PATENT AND TRADEMARK OFFICE, 2012). Para os requisitantes estrangeiros o ganho total estimado é de 8,7 bilhões de dólares ao longo dos cinco anos. Estes valores foram calculados considerando-se o aumento gerado no valor privado das patentes devido à redução do tempo de pendência. Ademais, o estudo faz uma importante relação entre o tempo de pendência, os incentivos à inovação e o crescimento econômico, ao afirmar que a redução no tempo de espera "significantly reduces uncertainty regarding the scope of patent rights, which fosters innovation and has a positive effect on economic growth" (UNITED STATES PATENT AND TRADEMARK OFFICE, 2012, p. 40).

Sob a hipótese de que a espera pelo resultado da patente influencia na formação das expectativas dos inventores, o presente trabalho tem por objetivo analisar o impacto do tempo de pendência sobre 
o crescimento de longo prazo da economia. Para tanto, consideramos um ambiente de equilíbrio geral dinâmico baseado no modelo schumpeteriano de crescimento endógeno com avanço de qualidade, desenvolvido originalmente por Grossman e Helpman (1991a,b) e Aghion e Howitt (1992). O processo competitivo entre os agentes inovadores e a mudança tecnológica descrita pelo modelo schumpeteriano constitui um importante avanço sobre o arcabouço teórico proposto pelo modelo de variedades de Romer (1990). O progresso tecnológico via inovação vertical (o avanço da qualidade dos bens já existentes), o efeito de captura dos lucros de monopólio (o efeito business-stealing, ou a "destruição criativa") e a endogeneização da taxa de ocorrência das novas tecnologias são exemplos dos aspectos presentes no modelo schumpeteriano que permitem analisar com uma maior acuidade questões relacionadas aos direitos de propriedade, à organização industrial, às instituições e às políticas de incentivo à inovação, se comparado ao modelo de Paul Romer.

Nossos resultados mostram que há uma relação negativa entre o crescimento e o tempo médio de pendência das patentes, de forma que períodos mais longos de espera geram uma perda social na forma de redução no consumo, no processo de inovação e no crescimento. Ao calibrar o modelo com os dados da economia brasileira para o ano de 2011 avaliamos que uma redução no tempo médio de pendência de 5,4 para 2,8 anos, considerando o tempo médio dos EUA como benchmark, elevaria a taxa de crescimento de longo prazo em 0,101 pontos percentuais, reduziria o tempo de surgimento de novas tecnologias de 8,02 para 7,24 anos e promoveria um ganho de bem-estar de $1,63 \%$ na forma de aumento do consumo. Estes resultados contribuem para a discussão sobre o impacto da pendência das patentes, e como uma redução eficiente no tempo de espera pode elevar o crescimento da economia.

Quanto à estrutura, este artigo é composto por mais três seções. Na segunda seção apresentamos as hipóteses e desenvolvemos o modelo schumpeteriano. A terceira seção destina-se à análise dos resultados, onde calibramos o modelo e comparamos o equilíbrio descentralizado com a solução do planejador social. A última seção traz as considerações finais e em seguida temos as referências bibliográficas.

\section{O MODELO ECONÔMICO}

Há três classes de agentes na nossa economia: os produtores do bem final, os inventores e as famílias. Para se gerar o produto final os produtores utilizam, além do trabalho, os insumos intermediários ofertados pelo setor de P\&D. A quantidade de bens intermediários é fixa, e o progresso tecnológico emerge na forma de avanços na qualidade de cada um dos intermediários existentes. Os bens intermediários de diferentes qualidades são substitutos perfeitos entre si, isto é, estamos em um ambiente de inovações drásticas (Aghion e Howitt, 1992). Os produtores do bem final demandam apenas a versão de maior qualidade de cada intermediário, o que incentiva os inventores a investir seus recursos visando evoluir a tecnologia e assim tornarem-se os únicos ofertantes do bem no mercado. No entanto, para se exercer o direito de monopólio sobre uma invenção é necessário obter uma patente junto ao escritório de patentes da economia. Como as patentes somente são concedidas após um tempo tomado como aleatório pelos pesquisadores, gera-se uma incerteza quanto à data a partir da qual o inventor poderá extrair seu lucro de monopólio, o que influencia na formação das expectativas do setor de P\&D. Por fim, temos as famílias, que ofertam trabalho e buscam maximizar sua utilidade ao longo de um horizonte temporal infinito, sujeitos a uma restrição orçamentária intertemporal. Por suposição, não há crescimento populacional.

\subsection{Os Produtores do Bem Final}

Nesta economia há um conjunto de firmas indexadas por $i \in[0,1]$ que produzem um bem final homogêneo. Cada produtor do bem final detém uma tecnologia de produção dada por: 


$$
Y_{i}(t)=A L_{i}^{1-\alpha} \cdot \int_{0}^{1}\left[q^{k_{j}(t)} X_{i j}(t)\right]^{\alpha} d j
$$

Suponha que há um contínuo de bens intermediários indexados por $j \in[0,1]$ cuja variedade é fixa no tempo. As firmas pertencentes ao setor do bem final utilizam na sua produção uma quantidade de trabalho $L_{i}$ e uma quantidade $X_{i j}(t)$ de cada bem intermediário existente, com $0<\alpha<1$ e eficiência produtiva medida pelo parâmetro $A$. Como o número de intermediários é fixo, sua medida pode ser normalizada para 1 . Supondo que a massa de produtores do bem final também é constante, sua medida ser normalizada para 1 sem perda de generalidade. Com isto, temos que $\int_{0}^{1} L_{i} d i=L$ é a quantidade total de trabalho empregado, constante por não haver crescimento populacional, e $\int_{0}^{1} X_{i j}(t) d i=X_{j}(t)$ é a quantidade total demandada de cada bem intermediário no tempo $t$. o produto final agregado, dado por $\int_{0}^{1} Y_{i}(t) d i=Y(t)$, é o numerário da economia.

O setor de P\&D é o responsável pelo progresso tecnológico da sociedade, que ocorre através de melhorias no nível de qualidade dos bens intermediários. A qualidade avança de forma proporcional a um fator $q, q>1$. Se $k$ inovações ocorreram com um intermediário ao longo do tempo, $k \in \mathbb{N}$, a sua qualidade atual mede $q^{k}$, onde $k=0$ é o instante em que o bem surge pela primeira vez no mercado (qualidade normalizada para 1) e $k=k_{j}$ é o avanço mais recente realizado sobre a qualidade do bem $j$.

A trajetória da qualidade dos bens intermediários é uma variável aleatória que se assemelha a uma escada (quality ladder), onde a altura dos degraus é proporcional a $q$ e a distância entre os degraus, isto é, o intervalo de tempo entre as qualidades $q^{k}$ e $q^{k+1}$, é estocástica. Logo, ao longo do tempo a qualidade de um intermediário permanece constante ou salta discretamente um degrau a uma razão $q$. O momento no tempo em que ocorre o salto de qualidade é aleatório, pois depende das incertezas enfrentadas pelo setor de P\&D. Como se observa pela equação (1), os produtores do bem final utilizam apenas os intermediários de maior qualidade em cada ponto no tempo.

As firmas produtoras do bem final são competitivas e tomam o preço dos bens intermediários e do trabalho como dados. Cada produtor maximiza seu lucro, dado pela diferença entre o valor da produção e os custos totais:

$$
\max _{X_{i j}(t), L_{i}} A L_{i}^{1-\alpha} \cdot \int_{0}^{1}\left[q^{k_{j}(t)} X_{i j}(t)\right]^{\alpha} d j-w(t) L_{i}-\int_{0}^{1} P_{j}(t) X_{i j}(t) d j
$$

onde $w(t)$ é o salário pago, $P_{j}(t)$ é o preço do intermediário $j$ e o produto $Y_{i}(t)$ é vendido ao preço normalizado de uma unidade. Assumindo-se que os bens intermediários são depreciados totalmente após o uso e que os trabalhadores são contratados de forma instantânea (spot market), o problema de maximização dos lucros do setor do bem final pode ser resolvido de forma separada para cada ponto no tempo. A condição de primeira ordem com relação a $X_{i j}(t) \forall j \in[0,1]$ nos dá a função demanda do intermediário $j$ para o $i$-ésimo produtor de bem final:

$$
X_{i j}(t)=L_{i} \cdot\left[A \alpha q^{\alpha k_{j}(t)} P_{j}(t)^{-1}\right]^{1 /(1-\alpha)}
$$

A condição de primeira ordem com relação a $L_{i}$ nos dá o valor do salário pago:

$$
w(t)=(1-\alpha) \cdot\left(Y_{i}(t) L_{i}^{-1}\right)
$$

Utilizando a equação (3) a demanda total pelo bem $j$ é dada por:

$$
X_{j}(t)=L \cdot\left[A \alpha q^{\alpha k_{j}(t)} P_{j}(t)^{-1}\right]^{1 /(1-\alpha)}
$$




\subsection{Setor de Pesquisa e Desenvolvimento}

Cada bem intermediário é criado e produzido em um diferente setor de pesquisa, cujo agregado compõe o setor de P\&D da economia. Os agentes que integram os $j$ setores de pesquisa enfrentam um processo de decisão composto por dois estágios. No primeiro os potenciais inventores decidem se investem seus recursos na tentativa de melhorar o nível de qualidade de um determinado bem intermediário. A decisão de entrar no mercado depende da condição de livre entrada do setor, onde a firma de pesquisa compara suas expectativas de lucro com os custos de P\&D.

Caso decida investir em pesquisa o inventor entra no segundo estágio de decisão, no qual submete um pedido de patente para seu produto. Se a patente for concedida, o inventor define o preço ótimo a ser cobrado pelo uso de sua invenção, e calcula o valor presente do fluxo de lucros que irá receber enquanto monopolista. $O$ valor presente dos lucros de um inventor depende não apenas do tempo de pendência de sua patente, mas também dos esforços de pesquisa e do tempo de pendência da patente dos seus concorrentes. Para a solução dos estágios seguiremos o princípio de resolução retroativa, começando pelo segundo estágio, onde se supõe que o inventor obterá com sucesso uma patente relativa a um avanço de qualidade no setor.

\subsubsection{Tempo de Pendência, Preço Ótimo de Monopólio e o Valor Esperado da Patente}

Seja $t_{k_{j}}$ o momento no tempo em que o $k$-ésimo inventor eleva com sucesso a qualidade do bem $j$ de $q^{k_{j}-1}$ para $q^{k_{j}}$. A partir deste instante o inventor submete um pedido de patente para seu produto, que será avaliado pelo escritório de patentes.

O escritório de patentes é capaz de avaliar, sem erro, se um avanço de qualidade foi de fato realizado sobre um determinado bem intermediário. Contudo, o tempo gasto para analisar e julgar qualquer pedido de patente é incerto. A variável aleatória $\tau_{k_{j}}, \tau_{k_{j}} \sim \operatorname{Exp}(\lambda)$, expressa o tempo de espera pelo resultado da patente de degrau de qualidade $k_{j}$. O tempo médio de pendência, dado por $E\left[\tau_{k_{j}}\right]=\lambda^{-1}$, é um parâmetro exógeno suposto constante no tempo e idêntico para todos os $j$ setores intermediários, cujo valor é fornecido à sociedade pelo escritório de patentes.

A hipótese de que o tempo de pendência segue uma distribuição exponencial traz uma importante vantagem do ponto de vista da resolução analítica do modelo, pois através dela conseguimos obter uma solução final fechada. Ademais, se o tempo de pendência é exponencialmente distribuído, períodos de espera mais curtos são mais prováveis de ocorrer do que períodos de espera mais longos. Isto representa o comportamento que iremos assumir para a atuação do escritório de patentes dentro da economia.

$\mathrm{O}$ intervalo $\left[t_{k_{j}}, t_{k_{j}}+\tau_{k_{j}}\right]$ corresponde ao período de incerteza enfrentado pelo inventor durante a pendência de seu pedido de patente. Ao longo deste período o pesquisador detém apenas uma expectativa de direito sobre seu produto, que somente se configura quando a patente é concedida. Dado que as firmas de P\&D não estão dispostas a correr o risco da imitação e que as mesmas não são capazes de cobrar o preço de monopólio sem a proteção dos direitos de propriedade, o inventor não oferta sua tecnologia no mercado até que a patente lhe seja concedida. Portanto, não há lucro gerado durante o período de pendência.

Os pedidos de patente são, por suposição, publicados no mesmo instante em que são depositados no escritório de patentes, o que torna seu conteúdo disponível para a consulta de qualquer agente do setor de P\&D. Isto permite aos inventores concorrentes, a partir de $t_{k_{j}}$, investir seus recursos em pesquisa baseados na qualidade $q^{k_{j}}$, com o intuito de produzir uma linha de qualidade superior.

Todos os bens intermediários possuem um custo marginal unitário de produção, independente do nível de qualidade do bem. Ou seja, o inventor da qualidade mais recente possui uma vantagem em comparação aos inventores anteriores, pois produz o bem intermediário de forma mais eficiente do que as gerações menos avançadas. As patentes não têm data de expiração, todavia os produtores do bem final demandam apenas o insumo de maior qualidade em cada um dos $j$ setores, o que incentiva 
os inventores a investir seus recursos visando evoluir o estado da arte e assim tornarem-se os únicos ofertantes do bem no mercado, expulsando as linhas de qualidade inferior.

Uma vez concedida, a patente confere ao inventor o direito de exclusividade sobre a produção e venda de sua criação. Seja $v, v \geq t_{k_{j}}+\tau_{k_{j}}$, cada instante no tempo após o $k$-ésimo inventor obter sua patente e colocar o seu produto no mercado. 0 fluxo de lucros recebido a partir de $v$ é dado por:

$$
\pi\left(k_{j}\right)=X_{j}(v) \cdot\left[P_{j}(v)-1\right]=L \cdot\left[A \alpha q^{\alpha k_{j}(v)} P_{j}(v)^{-1}\right]^{1 /(1-\alpha)}\left[P_{j}(v)-1\right]
$$

A condição de primeira ordem para a maximização dos lucros fornece o preço ótimo:

$$
P_{j}(v)=\alpha^{-1}
$$

O preço ótimo de monopólio é um markup sobre o custo marginal, sendo constante no tempo e entre os setores. Ao substituir a equação (7) na equação (5) encontra-se a quantidade total produzida do intermediário $j$ :

$$
X_{j}(v)=A^{1 /(1-\alpha)} \alpha^{2 /(1-\alpha)} L \cdot q^{\alpha k_{j}(v) /(1-\alpha)}
$$

A quantidade $X_{j}(v)$ e o preço $P_{j}(v)$ determinam o fluxo de lucros do monopólio, que depende positivamente do nível de qualidade:

$$
\begin{gathered}
\pi\left(k_{j}\right)=\bar{\pi} \cdot q^{\alpha k_{j}(v) /(1-\alpha)} \\
\bar{\pi} \equiv A^{1 /(1-\alpha)} \alpha^{2 /(1-\alpha)}(1-\alpha) \alpha^{-1} L
\end{gathered}
$$

$\mathrm{O} k$-ésimo inventor extrai os lucros de seu produto até o instante em que outro pesquisador obtém a patente para um novo avanço no degrau de qualidade, de $k_{j}$ para $k_{j}+1$. Seja $t_{k_{j}+1}$ o momento em que um inventor concorrente submete o pedido de patente para a qualidade $q^{k_{j}+1}$. O tempo de pendência enfrentado pelo $k$-ésimo +1 inventor é dado pela variável aleatória $\tau_{k_{j}+1}, \tau_{k_{j}+1} \sim \operatorname{Exp}(\lambda){ }^{1}{ }^{1} \mathrm{~A}$ duração do poder de monopólio do $k$-ésimo inventor pode então ser expressa da seguinte forma:

$$
\Psi\left(k_{j}\right)=t_{k_{j}+1}+\tau_{k_{j}+1}-\left(t_{k_{j}}+\tau_{k_{j}}\right)=T\left(k_{j}\right)+\tau_{k_{j}+1}-\tau_{k_{j}}
$$

onde $T\left(k_{j}\right)=t_{k_{j}+1}-t_{k_{j}}$. Em cada um dos $j$ setores desta economia os pedidos de patente que descrevem avanços no nível de qualidade são depositados no escritório de patentes segundo um processo estocástico de Poisson com intensidade $p_{j}$. Isto significa que, em um intervalo de tempo $\Delta t$, a quantidade de inovações realizadas sobre o bem $j$ segue uma distribuição de Poisson com parâmetro $p_{j} \Delta t$. Como a chegada dos pedidos de patente é governada por um processo de Poisson, o momento $t_{k_{j}+1}$ ocorre com probabilidade $p_{j}$ por unidade de tempo e o intervalo $T\left(k_{j}\right)$ segue uma distribuição exponencial com parâmetro $p_{j}$. Admite-se que o intervalo $T\left(k_{j}\right)$ e o tempo de pendência das patentes são variáveis aleatórias independentes.

Com base na duração do monopólio, o valor presente dos fluxos de lucro da qualidade $q^{k_{j}}$ é dado por:

$$
V=\int_{t_{k_{j}}+\tau_{k_{j}}}^{t_{k_{j}+1}+\tau_{k_{j}+1}} \pi\left(k_{j}\right) \cdot e^{-\int_{t_{k_{j}}}^{v} r(\omega) d \omega} d v
$$

\footnotetext{
${ }^{1}$ Ou seja, os pedidos de patente para níveis de qualidade mais avançados não necessariamente demoram mais para serem analisados do que os pedidos de qualidade inferior. Não há qualquer suposição neste modelo quanto à dificuldade do escritório de patentes em analisar e julgar os pedidos de diferentes tecnologias, exceto no que toca à aleatoriedade do tempo de exame. Para todos os níveis de qualidade, e em todos os $j$ setores, os períodos de pendência das patentes são variáveis aleatórias i.i.d. com distribuição exponencial de parâmetro $\lambda$.
} 
O inventor obtém o montante $\pi\left(k_{j}\right)$ em cada ponto do intervalo $\Psi\left(k_{j}\right)$, que corresponde ao seu tempo de monopólio. Todo o fluxo futuro de lucros é trazido para o momento $t_{k_{j}}$ utilizando como fator de desconto a taxa de juros da economia. Observe que enquanto o fluxo de lucros é calculado a partir de $t_{k_{j}}+\tau_{k_{j}}$, o fator de desconto presente é aplicado desde a data do pedido da patente. Esta estrutura permite captar o custo gerado pelo tempo de pendência, uma vez que durante este período o inventor não obtém lucro.

No equilíbrio de longo prazo a taxa de juros é constante no tempo. Utilizando esta condição na equação (11) e resolvendo a integral encontra-se:

$$
V\left[\tau_{k_{j}}, \tau_{k_{j}+1}, T\left(k_{j}\right)\right]=\left(\pi\left(k_{j}\right) / r\right) \cdot\left[e^{-r \tau_{k_{j}}}-e^{-r\left(T\left(k_{j}\right)+\tau_{k_{j}+1}\right)}\right]
$$

$O$ valor presente dos lucros do $k$-ésimo inventor é uma variável aleatória que depende positivamente do fluxo $\pi\left(k_{j}\right)$, do intervalo de tempo $T\left(k_{j}\right)$ até outro pesquisador depositar um pedido de patente para uma qualidade superior e do tempo de pendência da patente do concorrente, $\tau_{k_{j}+1}$. Por outro lado, $V$ é uma função decrescente em $\tau_{k_{j}}$. O valor esperado da patente de degrau de qualidade $k_{j}$ é dado pela esperança matemática da equação (12):

$$
E\left[V\left(k_{j}\right)\right]=\left[\pi\left(k_{j}\right) /\left(r+p_{j}\right)\right] \cdot[\lambda /(r+\lambda)]
$$

$\mathrm{O}$ valor da patente é função decrescente do tempo médio de pendência, da taxa de inovação e da taxa de juros. O termo $\lambda /(r+\lambda)$ é o fator de desconto sobre o valor privado da patente devido ao tempo de espera pela sua concessão. Como se observa, este fator depende da taxa de retorno, sendo endogenamente determinado no modelo.

A partir da equação (13) podemos expressar a taxa de retorno do mercado em função dos demais parâmetros:

$$
r=\left\{\left[\left(p_{j}+\lambda\right) / 2\right]^{2}+\lambda\left(\pi\left(k_{j}\right)-p_{j} E\left[V\left(k_{j}\right)\right]\right) / E\left[V\left(k_{j}\right)\right]\right\}^{1 / 2}-\left(p_{j}+\lambda\right) / 2
$$

Para se determinar a taxa de juros de equilíbrio é necessário especificar a lei de formação da taxa $p_{j}$, que é endógena, e o valor de $E\left[V\left(k_{j}\right)\right]$ a partir das condições de entrada no setor inovativo. Neste modelo suporemos livre entrada no setor de P\&D.

\subsubsection{A Decisão de Entrar no Setor de PED}

Seja $Z\left(k_{j}\right)$ o fluxo de recursos investido em pesquisa por todos os inventores que buscam obter uma patente para o degrau de qualidade $k_{j}+1$. Assuma que a taxa de inovação do bem $j$ é proporcional a $Z\left(k_{j}\right)$, isto é, quanto maior a quantidade total de recursos gastos em P\&D visando elevar o nível de qualidade do intermediário, maior é a probabilidade por unidade de tempo de um entrante inovar e submeter o seu pedido de patente.

Suponha também que o processo de avanço tecnológico torna-se cada vez mais difícil à medida que o nível de qualidade aumenta. Uma especificação que facilita a solução analítica do modelo é determinar que $p_{j}$ se reduz em proporção ao produto que será gerado ao se atingir um novo padrão de qualidade para o bem $j$. O produto final da economia pode ser obtido agregando-se a equação (1) sobre todos os produtores do bem final e substituindo $X_{j}(t)$ pela equação (8):

$$
Y(t)=A^{1 /(1-\alpha)} \alpha^{2 \alpha /(1-\alpha)} L \cdot \int_{0}^{1} q^{\alpha k_{j}(t) /(1-\alpha)} d j
$$

Observe que ao ocorrer um salto no degrau de qualidade do intermediário $j$, de $k_{j}$ para $k_{j}+1$, o produto será proporcional ao termo $q^{\alpha\left(k_{j}+1\right) /(1-\alpha)}$. Logo, uma forma funcional admissível para a taxa de inovação é dada por:

$$
p_{j}=Z\left(k_{j}\right) /\left(q^{\alpha\left(k_{j}+1\right) /(1-\alpha)} \cdot \eta\right)
$$


onde $\eta$ é um parâmetro que representa o custo fixo da pesquisa, $\eta>0$. A taxa $p_{j}$ é proporcional ao gasto total em P\&D com o bem $j$ e inversamente proporcional à contribuição do intermediário no produto da economia ao se atingir o nível subsequente de qualidade.

As firmas que estão na corrida pela patente $k_{j}+1$ possuem uma expectativa de lucro igual a $E\left[V\left(k_{j}+1\right)\right]$, que ocorre com probabilidade $p_{j}$ por unidade de tempo. Supondo que a recompensa líquida esperada do projeto de P\&D pode não ser suficientemente lucrativa, a livre entrada no setor implica:

$$
p_{j} \cdot E\left[V\left(k_{j}+1\right)\right]-Z\left(k_{j}\right) \leq 0
$$

Entretanto, se a desigualdade for estrita não há estímulos para a entrada de novos inventores, o que estancaria o progresso tecnológico. Estamos interessados em um espaço de parâmetros onde haja investimento positivo em P\&D, tal que $Z\left(k_{j}\right)>0$, o que é essencial para o crescimento econômico. Isto requer que a condição de livre entrada seja atendida na igualdade:

$$
p_{j} \cdot E\left[V\left(k_{j}+1\right)\right]-Z\left(k_{j}\right)=0
$$

As equações (18) e (16) determinam a condição de não arbitragem para haver investimento positivo em P\&D:

$$
\left(1 / q^{\alpha\left(k_{j}+1\right) /(1-\alpha)}\right) \cdot E\left[V\left(k_{j}+1\right)\right]=\eta
$$

Ao se investir $\eta$ unidades do produto final em pesquisa no intermediário com degrau de qualidade $k_{j}$ há uma probabilidade igual a $1 / q^{\alpha\left(k_{j}+1\right) /(1-\alpha)}$ por unidade de tempo de ocorrer uma inovação para o degrau $k_{j}+1$. Por sua vez, a patente para a nova qualidade tem valor igual a $E\left[V\left(k_{j}+1\right)\right]$.

Utilizando a equação (13) para $k_{j}+1$ e substituindo-a na equação (19) obtemos:

$$
p_{j}=p=\lambda \bar{\pi} /[\eta(r+\lambda)]-r
$$

No equilíbrio $p_{j}$ depende apenas de parâmetros constantes e da taxa de juros, que também é constante no longo prazo. Logo, a taxa em que surgem os pedidos de patente para avanços no nível de qualidade dos intermediários é idêntica para todos os $j$ setores da economia, e não depende do nível de qualidade.

Além disso, observa-se que o progresso tecnológico desta economia pode ser descrito em termos de um sistema de filas. Em notação de Kendall (1953), temos que o processo de requisição e concessão de patentes segue uma fila do tipo $M / M / \infty$ : a chegada dos pedidos de patente é governada por um processo de Poisson com parâmetro $p$, o tempo de atendimento, ou o tempo de pendência, é exponencialmente distribuído com parâmetro $\lambda$ e há infinitos atendentes independentes, isto é, todo pedido de patente tem sua análise iniciada de forma independente a partir do instante em que ocorre o depósito no escritório de patentes. Em um sistema de filas deste tipo não há, efetivamente, a formação de filas, tendo em vista que existe sempre um atendente disponível para analisar o pedido de patente de um inventor proveniente de qualquer um dos $j$ setores. O único tempo de espera existente no sistema é o tempo em que o pedido de patente está sob pendência de julgamento.

No contexto da teoria das filas há um importante teorema atribuído a Burke (1956). O teorema de Burke nos diz que em uma fila do tipo $M / M / \infty$ o processo de saída do sistema é Poisson com o mesmo parâmetro do processo de chegada. Isso significa que, na nossa economia, as novas qualidades chegam ao mercado na mesma taxa $p$ em que chegam os pedidos no escritório de patentes. 0 teorema de Burke garante, deste modo, que $p$ é taxa em que as inovações são incorporadas no produto final da economia, assim como $p$ é a taxa em que ocorre a substituição do monopolista atual por um entrante.

Através das equações (20) e (16) encontra-se o volume total de recursos destinado à pesquisa no setor $j$ : 


$$
Z\left(k_{j}\right)=q^{\alpha\left(k_{j}+1\right) /(1-\alpha)}[\lambda \bar{\pi} /(r+\lambda)-r \eta]
$$

O investimento em P\&D no setor $j$ aumenta ao longo do tempo, conforme o nível de qualidade se eleva. No entanto, a condição de livre entrada nos diz que a espera pelas patentes influencia a formação da taxa $p$ que baliza o processo inovativo. Consequentemente, o investimento em pesquisa torna-se função do tempo médio de pendência.

A equação (20) implica que a taxa de juros assume a forma:

$$
r=\left\{[(p+\lambda) / 2]^{2}+\lambda(\bar{\pi} / \eta-p)\right\}^{1 / 2}-(p+\lambda) / 2
$$

\subsection{As Famílias}

As famílias desejam maximizar sua utilidade agregada ao longo de um horizonte de tempo infinito, restritas ao orçamento disponível em cada instante. Assumimos um contínuo de famílias com massa normalizada para 1 que apresentam as mesmas preferências intertemporais: sua utilidade $u[C(t)]$ depende da quantidade consumida e por suposição assume a forma funcional CIES (elasticidade de substituição intertemporal constante).

$$
U=\int_{0}^{\infty} u[C(t)] \cdot e^{-\rho t} d t=\int_{0}^{\infty}\left[C(t)^{1-\theta}-1\right][1-\theta]^{-1} \cdot e^{-\rho t} d t
$$

A elasticidade de substituição intertemporal é dada pela constante $1 / \theta, \theta>0$, e o parâmetro $\rho$, $\rho>0$, representa a taxa de preferência temporal.

As famílias são competitivas e não há heterogeneidade entre os indivíduos. Isto nos permite utilizar o princípio da família representativa, a qual captura o comportamento médio do consumo de todas as famílias da economia. A família representativa está sujeita à seguinte restrição orçamentária:

$$
\dot{S}(t)=w(t) \cdot L+r(t) \cdot S(t)-C(t)
$$

Cada pessoa oferta inelasticamente uma unidade de trabalho por unidade de tempo, recebendo o salário $w(t)$ pelos serviços oferecidos. A renda total da família representativa é composta pela renda agregada do trabalho, $w(t) \cdot L$, e pela renda derivada da posse de um portfólio balanceado de ativos, $S(t)$, na forma de direitos sobre o valor de mercado de todas as firmas de P\&D, as quais pagam a taxa real de retorno $r(t)$. Os ativos são a riqueza das famílias, e a renda não consumida é utilizada para acumular mais ativos. Há equilíbrio no mercado de trabalho.

A partir das condições de primeira ordem do problema de otimização dinâmica das famílias obtemos a equação de Euler, que estipula a regra de crescimento do consumo:

$$
\dot{C}(t) / C(t)=[r(t)-\rho] \theta^{-1}
$$

A cada ponto no tempo os consumidores satisfazem a equação de Euler e assintoticamente atendem à condição de transversalidade:

$$
\lim _{t \rightarrow \infty} S(t) \cdot e^{-\int_{0}^{t} r(\omega) d \omega}=0
$$

\subsection{A Trajetória de Crescimento Balanceado}

Ao longo do tempo a economia está sujeita à restrição de recursos:

$$
Y(t) \geq C(t)+X(t)+Z(t)
$$


onde $X(t)$ é a produção total de bens intermediários, $C(t)$ é o consumo e $Z(t)$ é o gasto total em pesquisa e desenvolvimento. Seja o índice médio de qualidade dado por:

$$
Q(t) \equiv \int_{0}^{1} q^{\alpha k_{j}(t) /(1-\alpha)} d j
$$

O índice $Q(t)$ é uma média dos níveis de qualidade de todos os bens intermediários produzidos na economia. Através da equação (15) vemos que o produto final é proporcional a $Q(t)$ :

$$
Y(t)=A^{1 /(1-\alpha)} \alpha^{2 \alpha /(1-\alpha)} L \cdot Q(t)
$$

Um aumento na qualidade de qualquer bem intermediário eleva o índice $Q(t)$, e por sua vez promove uma expansão do produto agregado.

A quantidade total de intermediários produzidos na economia é encontrada ao se agregar a equação (8) sobre todos os $j$ setores:

$$
\int_{0}^{1} X_{j}(t) d j=X(t)=A^{1 /(1-\alpha)} \alpha^{2 /(1-\alpha)} L \cdot Q(t)
$$

O mesmo raciocínio aplicado sobre $Z\left(k_{j}\right)$ nos dá o gasto total em P\&D, cujo resultado também é proporcional ao índice $Q(t)$ :

$$
\int_{0}^{1} Z\left(k_{j}\right) d j=Z(t)=q^{\alpha /(1-\alpha)}[\lambda \bar{\pi} /(r+\lambda)-r \eta] \cdot Q(t)
$$

A partir da equação (4) o salário de equilíbrio é dado por:

$$
w(t)=(1-\alpha) A^{1 /(1-\alpha)} \alpha^{2 \alpha /(1-\alpha)} \cdot Q(t)
$$

Apesar de os níveis de qualidade evoluírem de forma discreta e aleatória, sua média $Q(t)$ é determinística. Isto porque se assume que os $j$ setores são pequenos, suficientemente numerosos e que as inovações são independentes entre os setores. Assim, utilizando como princípio a lei dos grandes números, a média dos níveis de qualidade de todos os diferentes setores é estável, o que permite uma trajetória suave e não estocástica para $Q(t)$, bem como para o produto e demais variáveis cuja trajetória é função do índice médio de qualidade.

Um equilíbrio nesta economia é definido pelas sequências $[C(t), X(t), Z(t)]_{t=0}^{\infty}$ que são consistentes com a maximização da utilidade das famílias, sequências $\left[P_{j}(t), X_{j}(t)\right]_{t=0}^{\infty}$ que maximizam o valor presente esperado do fluxo de lucros dos inventores que detêm uma patente para o intermediário de maior qualidade em cada setor, sequência $[Q(t)]_{t=0}^{\infty}$ que é determinada pela condição de livre entrada, sequências $[r(t), w(t)]_{t=0}^{\infty}$ que são consistentes com o market clearing e sequência $[S(t)]_{t=0}^{\infty}$ que atenda à restrição de recursos da economia.

Uma trajetória de crescimento balanceado, ou BGP (Balanced Growth Path), é definida como uma trajetória de equilíbrio de longo prazo onde o consumo $C(t)$ e o produto $Y(t)$ crescem a uma mesma taxa constante. Pela equação de Euler, para que o consumo cresça a uma taxa constante é necessário que a taxa de juros também seja constante. Estamos interessados em uma situação onde $r(t)=r^{*} \forall t$, onde $r^{*}$ é a taxa de juros no BGP.

A suposição de uma taxa de juros constante no equilíbrio foi utilizada anteriormente para encontrar o valor presente esperado dos lucros dos inventores. Ao substituir na equação de Euler a taxa de juros dada em (22), chega-se à seguinte equação para a taxa de crescimento do consumo:

$$
\dot{C}(t) / C(t)=\left\{\left\{[(p+\lambda) / 2]^{2}+\lambda(\bar{\pi} / \eta-p)\right\}^{1 / 2}-(p+\lambda) / 2-\rho\right\} \theta^{-1}
$$


Como o produto, a produção total de bens intermediários e o gasto agregado em P\&D são proporcionais a $Q(t)$, todos crescem à mesma taxa. Segue-se que no BGP o consumo também cresce à mesma taxa do índice médio de qualidade, e assim:

$$
\dot{Y}(t) / Y(t)=\dot{Z}(t) / Z(t)=\dot{X}(t) / X(t)=\dot{C}(t) / C(t)=\dot{Q}(t) / Q(t)=\gamma^{*}
$$

Contudo, como a probabilidade inovação é endógena, a taxa de crescimento ainda não está completamente especificada. A fim de encontrar a solução final do modelo é necessário antes avaliar o comportamento do índice médio de qualidade ao longo do tempo. Para tanto, utilizamos as propriedades do processo de Poisson e o fato de que a medida de setores produtores de bens intermediários foi normalizada para 1 . A variação no índice médio de qualidade em um intervalo de tempo $\Delta t$ é dada por:

$$
\begin{aligned}
& Q(t+\Delta t)-Q(t)=e^{-p \Delta t} Q(t)+(p \Delta t) e^{-p \Delta t} q^{\frac{\alpha}{(1-\alpha)}} Q(t)+ \\
& +\sum_{n=2}^{\infty} \frac{(p \Delta t)^{n} e^{-p \Delta t}}{n !} q^{\frac{n \alpha}{(1-\alpha)}} Q(t)-Q(t)
\end{aligned}
$$

O primeiro termo do lado direito da equação (35) nos dá a probabilidade de não haver inovação nos $j$ setores no intervalo $\Delta t$. O segundo termo refere-se à probabilidade de haver uma inovação em todos os setores, o que eleva a produtividade dos mesmos pelo fator $q^{\alpha /(1-\alpha)}$. O terceiro termo nos dá a probabilidade de que ocorra mais de uma inovação em todos os intermediários durante este intervalo de tempo. Dividindo ambos os lados da equação por $\Delta t$ e tomando os limites para $\Delta t \rightarrow 0$ chegamos ao seguinte resultado:

$$
\dot{Q}(t) / Q(t)=p \cdot\left[q^{\alpha /(1-\alpha)}-1\right]
$$

Como a taxa de inovação é função do tempo de pendência, o mesmo ocorre com o crescimento do índice médio de qualidade. Substituindo a taxa $p$ pela equação (20) tem-se:

$$
\dot{Q}(t) / Q(t)=\{\lambda \bar{\pi} /[\eta(r+\lambda)]-r\} \cdot\left[q^{\alpha /(1-\alpha)}-1\right]
$$

Em equilíbrio com plena utilização de recursos, o portfólio de ativos das famílias assume o valor:

$$
S(t)=\int_{0}^{1}\left(\frac{Z(t)[\bar{\pi} Q(t)]^{-1}-1}{Z(t)[\bar{\pi} Q(t)]^{-1}-\lambda(r+\lambda)^{-1}}\right) E\left[V\left(k_{j}\right)\right] d j<\int_{0}^{1} E\left[V\left(k_{j}\right)\right] d j
$$

O valor agregado dos ativos é determinado com base na restrição orçamentária da família representativa e nas equações (9), (13), (20), (29), (30), (31), (32) e (37). Neste ambiente, o tempo de espera incerto pela concessão das patentes reduz a riqueza das famílias, tendo em vista que, no equilíbrio, o valor do portfólio de ativos é inferior ao valor agregado das patentes.

Observa-se que muito embora a taxa de crescimento do índice médio de qualidade e do consumo sejam iguais no BGP, $\dot{C}(t) / C(t)$ é uma função positiva da taxa de juros, ao contrário de $\dot{Q}(t) / Q(t)$. Portanto, a taxa de juros de longo prazo resulta do ponto de equilíbrio onde $\dot{Q}(t) / Q(t)=\dot{C}(t) / C(t)$.

Ao igualar a equação de Euler à equação (37) encontramos o valor final para a taxa de juros no BGP:

$$
r^{*}=\left\{\left\{(\lambda \varphi-\rho)^{2}+4 \lambda \varphi[\rho+(\bar{\pi} / \zeta)(\varphi-1)]\right\}^{1 / 2}-(\lambda \varphi-\rho)\right\} \cdot(2 \varphi)^{-1}
$$

Tal que $\varphi \equiv\left[1+\theta\left(q^{\alpha /(1-\alpha)}-1\right)\right]$. A solução final para a taxa de crescimento da economia é determinada com o uso da equação de $r^{*}$ :

$$
\gamma^{*}=\left\{\left\{(\lambda \varphi-\rho)^{2}+4 \lambda \varphi[\rho+(\bar{\pi} / \zeta)(\varphi-1)]\right\}^{1 / 2}-[\lambda \varphi-\rho(1-2 \varphi)]\right\} \cdot(2 \varphi \theta)^{-1}
$$

Com base na equação (36) o valor de equilíbrio da taxa de inovação é dado por: 


$$
\begin{gathered}
p^{*}=\gamma^{*} /\left(q^{\alpha /(1-\alpha)}-1\right)= \\
=\left\{\left\{(\lambda \varphi-\rho)^{2}+4 \lambda \varphi[\rho+(\bar{\pi} / \zeta)(\varphi-1)]\right\}^{1 / 2}-[\lambda \varphi-\rho(1-2 \varphi)]\right\} \cdot \frac{1}{[2 \varphi(\varphi-1)]^{-1}}
\end{gathered}
$$

Assumimos que os parâmetros obedecem à restrição $r^{*}>\rho$, o que garante uma taxa positiva de crescimento. De acordo com a equação (39) essa restrição é dada por:

$$
\rho<\left[(\lambda / 2)^{2}+\lambda(\bar{\pi} / \eta)\right]^{1 / 2}-\lambda / 2
$$

A condição de transversalidade implica $r^{*}>\gamma^{*}$. Isto requer que os parâmetros atendam também a seguinte restrição:

$$
\rho>\left\{[\lambda(1-\theta) / 2]^{2}+(\bar{\pi} / \eta)\left[\lambda(1-\theta)^{2}(\varphi-1)\right] /(\varphi-1+\theta)\right\}^{1 / 2}-\lambda(1-\theta) / 2
$$

Neste modelo não há dinâmica de transição. No tempo $t=0$ os valores iniciais do consumo, do produto agregado, da quantidade total de intermediários produzida e do gasto total em P\&D são proporcionais a $Q(0)$, um ponto de partida suposto conhecido para o índice médio de qualidade. A partir de então todas estas variáveis entram no BGP e crescem à taxa $\gamma^{*}$.

Diferentemente do modelo schumpeteriano tradicional, os potenciais agentes inovativos estão agora sujeitos a um nível mais elevado de incerteza. Os pesquisadores internalizam não apenas a incerteza quanto à capacidade inventiva sua e de seus concorrentes, mas também a incerteza quanto ao momento em que os pedidos de patente (seu e de seus competidores) serão julgados. Isto influencia na formação das expectativas do setor de pesquisa, que por sua vez determinam a taxa de retorno e o processo de chegada dos pedidos de patente. É por meio da taxa de juros e da taxa inovação que o tempo de pendência influencia o crescimento da economia, dado que $\gamma^{*}$ depende de $r^{*}$ e $p^{*}$.

Na próxima seção analisamos os resultados obtidos com o modelo schumpeteriano, com o intuito de avaliar o impacto do tempo médio de pendência das patentes sobre a trajetória de crescimento da economia.

\section{CALIBRAÇÃO E ANÁLISE DOS RESULTADOS}

Com base na solução final para a taxa de juros no BGP, e dada sua relação com a taxa de crescimento e com a taxa de inovação, temos que $r^{*}, \gamma^{*}$ e $p^{*}$ são funções monotônicas crescentes e estritamente côncavas em $\lambda$ :

$$
\begin{gathered}
r_{\lambda}^{*}=\frac{(\lambda \varphi-\rho)+2[\rho+(\bar{\pi} / \eta)(\varphi-1)]}{2\left\{(\lambda \varphi-\rho)^{2}+4 \lambda \varphi[\rho+(\bar{\pi} / \eta)(\varphi-1)]\right\}^{1 / 2}}-\frac{1}{2}>0 \\
r_{\lambda \lambda}^{*}=-\frac{2 \varphi(\bar{\pi} / \eta)(\varphi-1)[\rho+(\bar{\pi} / \eta)(\varphi-1)]}{\left\{(\lambda \varphi-\rho)^{2}+4 \lambda \varphi[\rho+(\bar{\pi} / \eta)(\varphi-1)]\right\}^{3 / 2}}<0 \\
\gamma_{\lambda}^{*}=\frac{r_{\lambda}^{*}}{\theta}>0 \quad p_{\lambda}^{*}=\frac{r_{\lambda}^{*}}{(\varphi-1)}>0 \\
\gamma_{\lambda \lambda}^{*}=\frac{r_{\lambda \lambda}^{*}}{\theta}<0 \quad p_{\lambda \lambda}^{*}=\frac{r_{\lambda \lambda}^{*}}{(\varphi-1)}<0
\end{gathered}
$$

Como o parâmetro $\lambda$ responde pelo recíproco do tempo médio de pendência, conclui-se que economias onde as patentes são concedidas mais rapidamente apresentam uma taxa de crescimento mais elevada. Neste modelo, um maior período de espera pelas patentes desestimula a atividade inventiva, reduzindo o investimento em pesquisa e elevando o tempo médio com que surgem as novas tecnologias.

Analisando a condição de não arbitragem expressa na equação (19) vemos que um aumento no custo da pesquisa deve vir acompanhado de um aumento nas expectativas de lucro da invenção. $O$ aumento 
do custo por sua vez reduz a taxa de retorno e a taxa de inovação, o que é necessário para que haja um aumento no valor esperado da patente de acordo com a equação (13). Este é o motivo pelo qual, neste arcabouço schumpeteriano, os agentes produtores de tecnologia podem suportar distorções que aumentem o custo da pesquisa em detrimento de uma redução no crescimento da economia. É possível, por exemplo, que uma empresa com elevado poder político influencie o sistema de forma a fortalecer seus direitos de propriedade, o que representaria um aumento nos custos de entrada dos concorrentes. Isto reduziria a taxa de juros, a taxa de inovação e o crescimento, mas elevaria o valor esperado da patente do monopolista.

Por outro lado, se diferenciarmos a equação (13) com relação a $\lambda$ obtemos:

$$
\frac{\partial E\left[V^{*}\left(k_{j}\right)\right]}{\partial \lambda}=\frac{\pi\left(k_{j}\right)\left\{\left(r^{*} \varphi-\rho\right) r^{*}-r_{\lambda}^{*}\left[2 r^{*} \varphi+\lambda \varphi-\rho\right] \lambda\right\}}{\left\{\left[\left(r^{*}+p^{*}\right)\left(r^{*}+\lambda\right)\right]^{2}(\varphi-1)\right\}}=0
$$

Conforme o parâmetro $\lambda$ aumenta o fator de desconto $\lambda /\left(r^{*}+\lambda\right)$ presente na equação (13) tende a unidade, o que eleva o valor esperado do invento. Mas uma redução no tempo médio de pendência promove um ajuste na taxa de juros e na taxa de inovação, elevando $r^{*}$ e $p^{*}$ e, por conseguinte, reduzindo o valor presente esperado dos lucros. Com o sistema em equilíbrio estes efeitos se cancelam e a expectativa dos lucros não se altera.

Isto ocorre pois supusemos que todos os potenciais inventores, independentemente de sua posição na linha de qualidade, estão sujeitos à mesma distribuição exponencial para o tempo de pendência das patentes. Não só inventor contemporâneo que submete seu pedido de patente se beneficia de uma redução no tempo médio de pendência, mas também toda a geração seguinte de potenciais entrantes. Portanto, na modelagem aqui aplicada uma redução no tempo médio de pendência não altera o valor esperado da patente, mas globalmente a sociedade experimenta uma maior taxa retorno, um maior processo inovativo e uma maior taxa de crescimento.

Supondo uma situação em que o tempo médio de pendência tende a zero, a taxa de juros, a taxa de crescimento e a taxa de inovação tendem assintoticamente para os seguintes valores:

$$
\begin{aligned}
\lim _{\lambda \rightarrow \infty} r^{*}(\lambda) & =[\rho+(\bar{\pi} / \eta)(\varphi-1)] \varphi^{-1}=r^{* *} \\
\lim _{\lambda \rightarrow \infty} \gamma^{*}(\lambda) & =[(\varphi-1) / \theta](\bar{\pi} / \eta-\rho) \varphi^{-1}=\gamma^{* *} \\
\lim _{\lambda \rightarrow \infty} p^{*}(\lambda) & =(\bar{\pi} / \eta-\rho) \varphi^{-1}=p^{* *}
\end{aligned}
$$

As taxas $r^{* *}$, $\gamma^{* *}$ e $p^{* *}$ correspondem aos resultados encontrados quando a patente é instantaneamente concedida ao inventor no momento em que um avanço de qualidade é atingido. Para qualquer conjunto admissível de parâmetros temos sempre $r^{* *}>r^{*}, \gamma^{* *}>\gamma^{*}$ e $p^{* *}>p^{*}$. Nossas hipóteses relativas ao funcionamento do sistema de concessão de patentes, bem como as relativas ao comportamento dos inventores perante este ambiente, acabam por generalizar os resultados do modelo schumpeteriano. No caso particular em que o tempo médio de pendência é suposto infinitesimal, as $\operatorname{taxas} r^{* *}, \gamma^{* *}$ e $p^{* *}$ são encontradas.

Com base nestes resultados calibramos o modelo com os dados da economia brasileira para o ano de 2011, com o objetivo de calcular a variação na trajetória de crescimento e no bem-estar gerada por uma mudança no tempo médio de pendência das patentes. O Quadro 1 apresenta os parâmetros calibrados e a fonte utilizada para a obtenção dos seus valores. 
Quadro 1 - Valores dos parâmetros e calibração do modelo

\begin{tabular}{l|c|c}
\hline Parâmetros & Valores & Fonte \\
\hline Inverso do tempo médio de pendência $(\lambda)$ & 0,1852 & INPI \\
Probabilidade de aprovação no BGP $\left(p^{*}\right)^{2}$ & 0,1246 & INPI \\
Taxa de preferência temporal $(\rho)^{3}$ & 0,0208 & Lledo (2005) \\
Elasticidade de substituição intertemporal $(1 / \theta)^{4}$ & 0,4 & Lledo (2005) \\
Participação dos bens intermediários no produto final $(\alpha)$ & 0,5 & Cavalcanti e Silva (2010) \\
Relação consumo/produto $(C(0) / Y(0))$ & 0,6033 & IBGE \\
Taxa real de juros no BGP $\left(r^{*}\right)^{5}$ & 0,0440 & BACEN e IBGE \\
Relação lucro/custo da pesquisa $(\bar{\pi} / \eta)$ & 0,2087 & Calibrado \\
Fator de avanço de qualidade $(q)$ & 1,0745 & Calibrado \\
Taxa de crescimento de longo prazo $\left(\gamma^{*}\right)$ & 0,00928 & Calibrado \\
\hline
\end{tabular}

Fonte: Elaboração própria dos autores.

A variação de bem-estar foi calculada com base na metodologia adotada por Ferreira e Araújo (1999) e Paes e Bugarin (2006), que utilizam a variação compensada do consumo para avaliar a perda ou ganho de bem-estar. Através desta abordagem calcula-se a quantidade de consumo que deve ser destinada ou retirada das famílias a fim de que, dado uma mudança de cenário, mantenham o mesmo nível de utilidade de que dispunham anteriormente.

Supondo-se dois cenários diferentes, um inicial (0) e outro final (1), a variação de bem-estar entre os cenários é dada por:

$$
\mathrm{VBE}=[C(0) / Y(0)]\left[1-\left(r_{1}^{*}-\gamma_{1}^{*}\right) /\left(r_{1}^{*}-\gamma_{1}^{*}\right)\right]
$$

onde $\gamma_{0}^{*}$ e $\gamma_{1}^{*}$ são, respectivamente, as taxas de crescimento no cenário inicial e final, $r_{1}^{*}$ é a taxa de juros no cenário final e $C(0) / Y(0)$ é a relação entre o consumo e o produto agregado da economia no cenário inicial. Se $\gamma_{0}^{*}<\gamma_{1}^{*}$ então VBE $>0$, significando que no cenário final há um ganho de bem-estar em termos de aumento do consumo como proporção do PIB.

A Tabela 1 contém valores calculados para $r^{*}, \gamma^{*}, p^{*}$ e para a variação do bem-estar. Supomos uma redução contínua no tempo médio de pendência das patentes, com ponto inicial em 5,4 anos, que corresponde ao tempo médio de decisão do INPI registrado em 2011, e ponto final em 2,8 anos, que corresponde ao encontrado nos EUA em 2011. Para os demais parâmetros fixamos os valores

\footnotetext{
${ }^{2}$ Como proxy para a taxa de inovação utilizamos a taxa de concessão dos pedidos de patentes no INPI. O United States Trademark Office (USPTO), o escritório norte-americano de patentes, calcula a taxa de concessão dos pedidos de patentes como a relação entre a quantidade de pedidos concedidos e o total de decisões de patentes em um determinado período. No fim de 2011 a taxa de concessão do USPTO era de 48\%, conforme consta em <http://www.uspto.gov/dashboards/patents/kpis/kpiAllowed.kpixml>. Apesar de no portal do INPI não constar nenhuma informação relativa à sua taxa de concessão, utilizamos aqui o mesmo conceito adotado pelo USPTO. Dado que em 2011 foram concedidos 3.801 pedidos de patentes no INPI e houve um total de 30.492 decisões, a taxa de concessão foi de $12,46 \%$.

${ }^{3} \mathrm{O}$ valor da taxa de preferência temporal foi obtido transformando-se para o caso contínuo o valor em tempo discreto dado em Lledo (2005).

${ }^{4} \mathrm{~A}$ elasticidade de substituição intertemporal também foi adaptada para o nosso modelo, sendo igual ao inverso daquela apresentada em Lledo (2005).

${ }^{5}$ A taxa real de juros no BGP foi calculada pela diferença entre a Taxa Selic em dezembro de 2011 e o IPCA acumulado no mesmo ano. O IPCA acumulado em 2011 atingiu o valor de 6,5\% e a Taxa Selic ao final do ano foi de 10,90\%.
} 
apresentados no Quadro 1. Observa-se que um tempo médio de espera menor pelas patentes contribui para elevar a taxa de retorno, a taxa de inovação e a taxa de crescimento da economia, conforme demonstrado anteriormente.

Tabela 1: Tempo médio de pendência das patentes, variação de bem-estar e as taxas de longo prazo

\begin{tabular}{c|c|c|c|c}
\hline $\begin{array}{c}\text { Tempo médio de } \\
\text { pendência, em anos }\end{array}$ & $p^{*}$ & $r^{*}$ & $\gamma^{*}$ & VBE \\
\hline 5,4 & 0,12460 & 0,04400 & 0,00928 & 0,01629 \\
5,2 & 0,12551 & 0,04417 & 0,00935 & 0,01522 \\
5,0 & 0,12645 & 0,04434 & 0,00942 & 0,01412 \\
4,8 & 0,12740 & 0,04452 & 0,00949 & 0,01299 \\
4,6 & 0,12837 & 0,04470 & 0,00956 & 0,01183 \\
4,4 & 0,12936 & 0,04489 & 0,00963 & 0,01065 \\
4,2 & 0,13037 & 0,04507 & 0,00971 & 0,00944 \\
4,0 & 0,13140 & 0,04527 & 0,00979 & 0,00819 \\
3,8 & 0,13246 & 0,04546 & 0,00987 & 0,00692 \\
3,6 & 0,13354 & 0,04566 & 0,00995 & 0,00561 \\
3,4 & 0,13464 & 0,04587 & 0,01003 & 0,00426 \\
3,2 & 0,13577 & 0,04608 & 0,01011 & 0,00288 \\
3,0 & 0,13692 & 0,04629 & 0,01020 & 0,00146 \\
2,8 & 0,13810 & 0,04651 & 0,01029 & 0,00000 \\
\hline
\end{tabular}

Fonte: Elaboração própria dos autores.

Ao atingir o benchmark de 2,8 anos para o tempo médio de pendência há um aumento de 0,101 pontos percentuais na taxa de crescimento, além de uma redução de $9,72 \%$ no tempo médio de surgimento de novas tecnologias, de 8,02 para 7,24 anos. As taxas limite do modelo calibrado são dadas por $p^{* *}=0,15837, r^{* *}=0,05029$ e $\gamma^{* *}=0,01180$. A Figura 1 ilustra o comportamento das taxas de longo prazo para valores crescentes do parâmetro $\lambda$ :

Infere-se também a partir da calibração do modelo que uma redução de 5,4 para 2,8 anos no tempo médio de pendência gera no longo prazo um ganho de bem-estar de $1,629 \%$ na forma de aumento do consumo. Estes resultados corroboram a importância de se criar políticas e mecanismos para se reduzir de forma eficiente o tempo gasto na análise e julgamento dos pedidos de patente na nossa economia. Isto reduziria a incerteza dos potenciais inventores e ampliaria o fluxo de recursos investidos em pesquisa e desenvolvimento, aumentando a probabilidade de se produzir inovações tecnológicas. 0 resultado é um aumento do consumo, da taxa de retorno e do crescimento no longo prazo.

De todo modo, a discussão de uma programação eficiente de políticas exige a comparação do equilíbrio descentralizado com a alocação pareto ótima resultante da solução do problema do planejador social. $\mathrm{O}$ equilíbrio descentralizado neste modelo schumpeteriano não é pareto ótimo devido às distorções causadas pelo preço de monopólio, pelo espalhamento do conhecimento acumulado, pelo tempo de pendência e pelo efeito business stealing. As três primeiras distorções tendem a reduzir a taxa de crescimento da economia competitiva em relação ao ótimo social. Porém, a possibilidade de expropriação dos lucros de monopólio pelos entrantes pode estimular demasiadamente a competição no setor de P\&D, gerando um investimento excessivo em inovação. Por conseguinte, o efeito business 
Figura 1: Relação entre o parâmentro $\lambda$ e as taxas de longo prazo

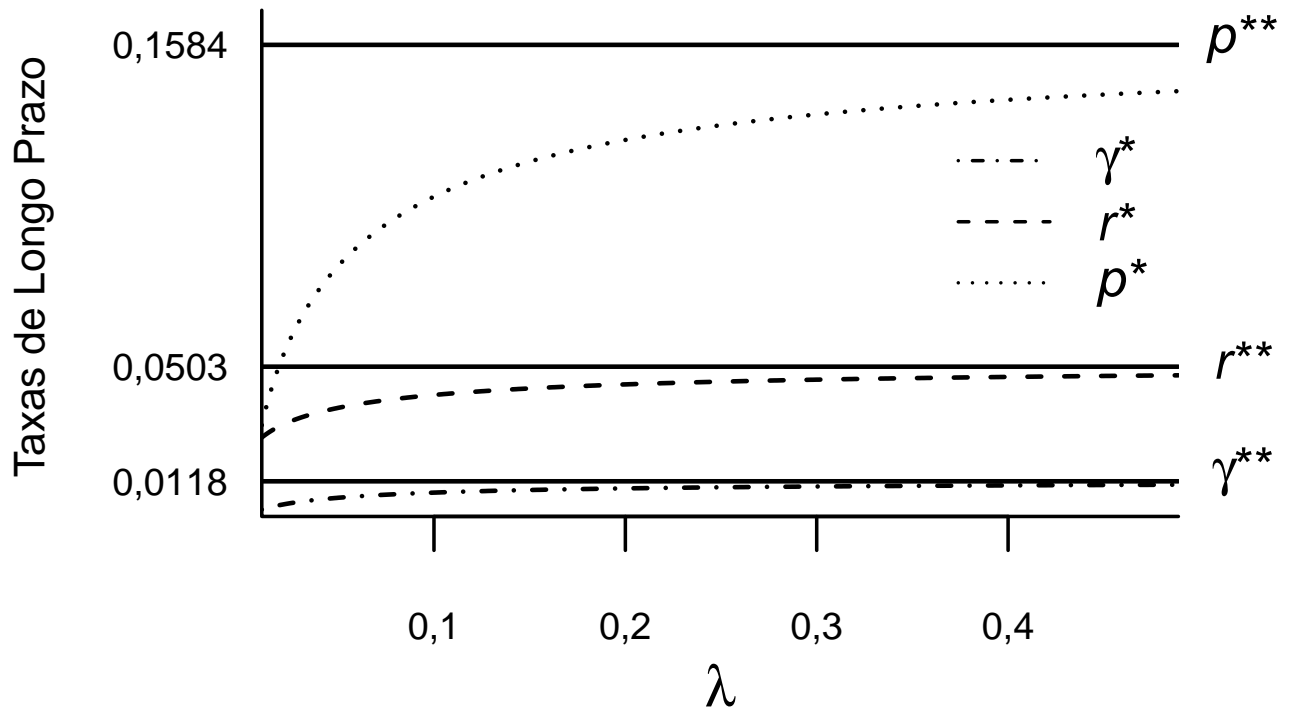

stealing pode fazer com que a taxa de crescimento da economia competitiva seja muito elevada se comparada à taxa socialmente ótima.

O planejador social busca maximizar a utilidade das famílias utilizando a tecnologia de produção $Y(t)=A L^{1-\alpha} \int_{0}^{1}\left[q^{k_{j}(t)} X_{j}(t)\right]^{\alpha} d j$, sujeito à restrição de recursos $Y(t)=C(t)+$ $\int_{0}^{1} X_{j}(t) d j+\int_{0}^{1} Z\left(k_{j}\right) d j$. O planejador também está sujeito à restrição tecnológica de $\mathrm{P} \& \mathrm{D}$, dada por $q^{\alpha\left(k_{j}+1\right) /(1-\alpha)} p_{j}=Z\left(k_{j}\right) \eta_{P S}^{-1}$, onde se supõe $\eta_{P S} \leq \eta$ uma vez que o planejador concede a atividade de pesquisa ao inventor que apresenta o menor custo de P\&D. A utilidade das famílias continua sendo representada pela equação (23).

A condição de primeira ordem para a maximização da utilidade com relação à quantidade produzida de bens intermediários, supondo um ambiente estático, nos fornece: $X_{j}(t)_{P S}=$ $(A \alpha)^{1 /(1-\alpha)} q^{\alpha k_{j} /(1-\alpha)} L$. Substituindo $X_{j}(t)_{P S}$ em $Y(t)$ encontramos o produto agregado da economia: $Y(t)_{P S}=A^{1 /(1-\alpha)} \alpha^{\alpha /(1-\alpha)} L Q(t)$. Integrando ambos os lados da restrição tecnológica de P\&D com relação à medida dos setores de bens intermediários, e dado que $p_{j}$ é constante, obtemos: $q^{\alpha /(1-\alpha)} Q(t) p=Z(t) \eta_{P S}^{-1}$. Utilizando o mesmo raciocínio aplicado na equação (35) encontramos a equação de acumulação de $Q(t): \dot{Q}=Z(t)\left[1-q^{-\alpha /(1-\alpha)}\right] \eta_{P S}^{-1}$. Através destes resultados o Hamiltoniano do problema do planejador social pode ser escrito da seguinte forma:

$$
\begin{aligned}
& H=\left[C(t)^{1-\theta}-1\right](1-\theta)^{-1} e^{-\rho t}+ \\
& +\mu(t) \cdot\left[A^{1 /(1-\alpha)} \alpha^{1 /(1-\alpha)}(1-\alpha) \alpha^{-1} L Q(t)-Z(t)-C(t)\right]+ \\
& +\phi(t) \cdot Z(t)\left[1-q^{-\alpha /(1-\alpha)}\right] \eta_{P S}^{-1}
\end{aligned}
$$

As condições de primeira ordem nos fornecem a seguinte solução ótima:

$$
\begin{aligned}
& \gamma_{P S}^{*}=\left[\left(\bar{\pi}_{P S} / \eta_{P S}\right)(\varphi-1) /(\theta+\varphi-1)-\rho\right] \theta^{-1} \\
& r_{P S}^{*}=\left(\bar{\pi}_{P S} / \eta_{P S}\right)(\varphi-1) /(\theta+\varphi-1)
\end{aligned}
$$


onde $\bar{\pi}_{P S} \equiv A^{1 /(1-\alpha)} \alpha^{1 /(1-\alpha)}(1-\alpha) \alpha^{-1} L \equiv \alpha^{-1 /(1-\alpha)} \bar{\pi}>\bar{\pi}$ e $r_{P S}^{*}$ é a taxa de retorno implícita no ótimo social. Além do custo $\eta$ há três distorções presentes na economia descentralizada que reduzem a taxa de crescimento em relação ao socialmente ótimo: a distorção estática causada pelo preço de monopólio, a distorção gerada pelo spillover das invenções e a distorção devido ao tempo de espera pelas patentes. Quanto à primeira, vimos que o monopolista cobra um markup sobre o custo marginal do intermediário. O markup de monopólio provoca uma redução na quantidade demandada de intermediários, gerando uma perda de eficiência estática na economia. O planejador social elimina esta distorção, uma vez que cobra pelo uso dos bens intermediários o seu custo marginal de produção. Como a economia planejada aloca mais recursos na produção dos bens intermediários, temos $X_{j}(t)_{P S}>X_{j}(t)$ para um dado nível de qualidade. Isto gera um ganho estático no produto agregado $Y(t)_{P S}$ e resulta em $\bar{\pi}_{P S}>\bar{\pi}$ na taxa ótima.

O fato de os inventores enxergarem o benefício de sua invenção como temporário também faz a taxa de crescimento da economia competitiva cair em relação à taxa ótima. Quando ocorre um avanço de qualidade a produtividade de um setor aumenta permanentemente no fator $q^{\alpha /(1-\alpha)}$, porém o retorno que o inventor obtém devido à sua contribuição na melhoria do estoque tecnológico é temporário. 0 próximo entrante obterá um ganho baseado em um nível de produtividade superior, sem que com isso tenha que compensar o seu antecessor pelos esforços realizados. O planejador, por sua vez, enxerga que cada melhoria na qualidade gera um beneficio social permanente, isto é, ele internaliza os spillovers de produtividade das invenções, o que tende a elevar a taxa de crescimento da economia planejada.

O tempo de espera pelas patentes é a terceira distorção presente neste modelo que tende a reduzir a taxa de crescimento em relação ao ótimo social. o tempo de pendência provoca dois efeitos: os inventores descontam mais o seu fluxo de lucros, o que reduz o valor privado da patente, e há uma redução na taxa de retorno e na taxa de inovação, o que eleva o valor da patente. O efeito líquido é a manutenção do retorno esperado associado a uma perda social na forma de redução no crescimento. Na economia planejada esta distorção é eliminada, pois o planejador não internaliza o tempo de pendência na decisão social do processo inovativo. Por este motivo a alocação pareto-ótima não é afetada pelo tempo de espera e a taxa de crescimento $\gamma_{P S}^{*}$ não se torna função do tempo médio de pendência das patentes.

Por outro lado, o efeito de captura dos lucros de monopólio, ou efeito business stealing, tende a elevar a taxa de crescimento em relação à taxa ótima, podendo provocar uma situação em que o processo competitivo torna-se excessivo se comparado ao socialmente desejado. Como se observa neste modelo, os inventores buscam melhorar o nível de qualidade com o intuito de capturar os lucros de monopólio do líder, mas ao fazê-lo acabam por destruir o fluxo de renda que motivou a criação anterior. Este efeito, que não tem valor social, tende a incentivar de forma excessiva os investimentos em P\&D. E quanto maior o volume de recursos destinado à pesquisa, menor é o retorno esperado das invenções. Na economia planejada esta distorção deixa de existir, pois o planejador identifica que cada nova tecnologia destrói o retorno social das invenções anteriores.

Se a desigualdade $\bar{\pi}_{P S} / \eta_{P S}>[(\theta+\varphi-1) / \varphi][\bar{\pi} / \eta+\rho /(\varphi-1)]$ for observada, as taxas de crescimento resultam em $\gamma^{*}<\gamma^{* *}<\gamma_{P S}^{*}$ e a distorção causada pelo efeito de captura não é capaz sobrepujar o crescimento ótimo. Caso contrário, a economia pode experimentar competição excessiva. Por exemplo, considerando-se os parâmetros calibrados para a economia brasileira e supondo $\eta_{P S}=\eta$ temos $\gamma^{*}=0,928 \%, \gamma^{* *}=1,180 \%$ e $\gamma_{P S}^{*}=1,482 \%$. Neste caso, $\gamma^{*}<\gamma^{* *}<\gamma_{P S}^{*}$ e a taxa de crescimento de longo prazo da economia brasileira encontra-se abaixo da socialmente ótima. Agora suponha $\eta_{P S}=\eta$ e que há um aumento nos custos da pesquisa de forma que a relação $\bar{\pi} / \eta$ cai de 0,2087 para 0,14 . Isto resultaria nas taxas $\gamma^{*}=0,606 \%, \gamma^{* *}=0,748 \%$ e $\gamma_{P S}^{*}=0,721 \%$. Apesar de a taxa $\gamma^{*}$ ainda ser inferior à taxa de crescimento social, a taxa $\gamma^{* *}$ torna-se agora superior. Neste cenário, a magnitude da distorção do tempo de pendência tende a ser superior ao efeito de captura, tornando a taxa de crescimento descentralizada inferior à taxa ótima. Porém, se o tempo médio de exame das patentes for suficientemente baixo, a sua distorção negativa acaba não superando a distorção para cima 
do efeito de captura. A taxa de crescimento torna-se então superior à taxa ótima, evidenciando os gastos excessivos em P\&D e uma corrida pelas patentes além do socialmente desejado. ${ }^{6}$

Na hipótese de haver crescimento insuficiente na economia descentralizada, de sorte que $\gamma^{*}<$ $\gamma_{P S}^{*}<\gamma^{* *}$, uma redução eficiente no tempo de análise e julgamento dos pedidos de patente pode contribuir para elevar a taxa de crescimento em direção à taxa socialmente ótima. Uma política de redução do tempo médio de pendência apresenta uma vantagem sobre uma política de subsídio ou compensação, pois o tomador de políticas não precisa identificar aqueles que devem ser corretamente beneficiados, o que geralmente se mostra um desafio. ${ }^{7}$ De um modo geral, os escritórios de patentes têm como uma de suas principais metas a redução do tempo médio de pendência. No caso do Brasil, o INPI planeja reduzir o tempo médio de análise para 4 anos, visando com isso se enquadrar no padrão internacional. Para este fim, o órgão conta com diversos projetos, como a contratação de novos examinadores (455 examinadores até janeiro de 2014), a introdução de um novo sistema on-line, o e-patentes, e a opinião preliminar sobre patentabilidade. ${ }^{8}$ Segundo declarações da presidência do INPI, o órgão espera que as melhorias implantadas estimulem a inovação tecnológica, aumentando os pedidos de patente em 20\%. ${ }^{9}$ Em consonância com os nossos resultados, podemos concluir que estes esforços do INPI contribuem para melhorar a eficiência do sistema de propriedade intelectual no Brasil, reduzindo a incerteza dos agentes e fomentando o progresso tecnológico.

\section{CONSIDERAÇÕES FINAIS}

Neste trabalho procuramos analisar a influência do tempo de pendência das patentes sobre o crescimento de longo prazo da economia, utilizando como base o modelo schumpeteriano de crescimento endógeno com avanço de qualidade. Nossos resultados mostram que há uma relação negativa entre o tempo médio de pendência e as taxas de longo prazo, de forma que períodos de espera mais longos pela decisão da patente provocam uma redução no crescimento, na taxa de retorno, no processo de avanço tecnológico e no bem-estar da sociedade via perda de consumo no longo prazo.

As hipóteses aqui empregadas podem ser estendidas de diversas formas. Pode-se, por exemplo, admitir que o tempo de pendência é formado tanto por um componente aleatório como por um componente endógeno, o que permitiria avaliar os fatores responsáveis pelo aumento ou redução do tempo de espera pelas patentes. Pode-se supor também que as patentes requisitadas pelos setores mais avançados da economia são mais rapidamente concedidas devido ao acúmulo de conhecimento gerado no escritório de patentes, na linha do que sugere Régibeau e Rockett (2010). Outro ponto relevante seria considerar, a exemplo do que discute King (2003), que uma redução no tempo de pendência sem

\footnotetext{
${ }^{6}$ Se $\bar{\pi} / \eta=0,1$ teríamos $\gamma^{* *}=0,497 \%>\gamma^{*}=0,407 \%>\gamma_{P S}^{*}=0,227 \%$. Neste caso a distorção gerada por um tempo médio de pendência de 5,4 anos não seria suficiente para trazer a taxa de crescimento abaixo da ótima, evidenciando uma maior magnitude do efeito business stealing.

${ }^{7}$ O governo também poderia contornar a distorção gerada pelo tempo de pendência através de um subsídio à pesquisa, de forma a compensar os pesquisadores pelo tempo em que esperam pela patente. Um subsídio à pesquisa reduziria os custos de entrada, elevando a taxa de inovação e a taxa de retorno. Porém, isto intensificaria o efeito business stealing, provocando uma redução no retorno esperado das invenções. Ademais, entre os principais problemas do subsídio à pesquisa estão a forma de financiamento do subsídio, que não pode ser distorciva, e a dificuldade em identificar corretamente os agentes que precisam ser subsidiados.

${ }^{8} \mathrm{O}$ sistema on-line e-patentes entrou em plena operação a partir de 20 de março de 2013 e permite que os inventores submetam e acompanhem seus pedidos pela internet. Mais detalhes sobre o sistema podem ser obtidos em http://epatentes.inpi . gov.br. Já a opinião preliminar sobre patentabilidade, cujo programa piloto foi iniciado em 2012, consiste em um relatório emitido por um examinador de patentes onde consta uma avaliação preliminar sobre a possibilidade do pedido de patente ser aprovado. O objetivo é que o depositante obtenha uma opinião prévia do seu pedido de patente de forma mais rápida, em cerca de três meses, o que garante mais segurança e agilidade na negociação da tecnologia. Informações adicionais sobre o processo de opinião preliminar podem ser obtidas em http://www.inpi.gov.br/portal/artigo/opiniao_preliminar.

${ }^{9}$ Sobre a matéria do lançamento do e-patentes e a declaração do presidente do INPI, ver http://www.inpi.gov.br/portal/ artigo/pedidos_de_patentes_ja_podem_ser_feitos_pela_internet.
} 
um correspondente aumento na eficiência dos exames pode distorcer o sistema, tendo em vista que os avaliadores do escritório de patentes poderiam não ter tempo hábil suficiente para realizar um exame minucioso de cada pedido, aumentando a probabilidade de ser concedida inapropriadamente uma patente a uma invenção que não atende em sua totalidade os requisitos de patentabilidade. Estas hipóteses, dentre outras, contribuiriam para enriquecer o modelo e permitiriam aprofundar a discussão sobre a importância da pendência das patentes para a formação das expectativas dos inventores e como isto influencia na mudança tecnológica e no crescimento econômico.

\section{BIBLIOGRAFIA}

Aghion, P., Bloom, N., Blundell, R., Griffith, R., \& Howitt, P. (2005). Competition and innovation: An inverted-U relationship. The Quarterly Journal of Economics, 120(2):701-728.

Aghion, P., Harris, C., Howitt, P., \& Vickers, J. (2001). Competition, imitation and growth with step-by-step innovation. The Review of Economic Studies, 68(3):467-492.

Aghion, P. \& Howitt, P. (1992). A model of growth through creative destruction. Econometrica, 60(2):323-351.

Burke, P. J. (1956). The output of a queuing system. Operations Research, 4(6):699-704.

Cavalcanti, M. \& Silva, N. (2010). Impactos de políticas de desoneração do setor produtivo: Uma avaliação a partir de um modelo de gerações superpostas. Estudos Econômicos, 40(4):943-966.

Ferreira, P. \& Araújo, C. (1999). Reforma tributária, efeitos alocativos e impactos de bem-estar. Revista Brasileira de Economia, 53(2):133-166.

Grossman, G. M. \& Helpman, E. (1991a). Quality ladders and product cycles. The Quarterly Journal of Economics, 106(2):557-586.

Grossman, G. M. \& Helpman, E. (1991b). Quality ladders in the theory of growth. The Review of Economic Studies, 58(1):43-61.

Grossman, G. M. \& Helpman, E. (1994). Endogenous innovation in the theory of growth. The Journal of Economic Perspectives, 8(1):23-44.

Helpman, E. (1993). Innovation, imitation, and intellectual property rights. Econometrica, 61(6):1247-1280.

Kendall, D. G. (1953). Stochastic processes occurring in the theory of queues and their analysis by the method of the imbedded markov chain. The Annals of Mathematical Statistics, pages 338-354.

King, J. L. (2003). Patent examination procedures and patent quality. In Cohen, W. M., Merrill, S. A., et alii, editors, Patents in the knowledge-based economy, pages 54-73. The National Academies Press, Washington, DC.

Kortum, S. S. (1997). Research, patenting, and technological change. Econometrica, pages 1389-1419.

Lledo, V. (2005). Tax systems under fiscal adjustment: A dynamic cge analysis of the Brazilian tax reform. International Monetary Fund, IMF Working Paper n. 05/142.

London Economics (2010). Economic Study on Patent Backlogs and a System of Mutual Recognition. Final Report prepared for the Intellectual Property Office. 
Paes, N. \& Bugarin, M. (2006). Reforma tributária: Impactos distributivos, sobre o bem-estar e a progressividade. Revista Brasileira de Economia, 60(1):33-56.

Régibeau, P. \& Rockett, K. (2010). Innovation cycles and learning at the patent office: Does the early patent get the delay? The Journal of Industrial Economics, 58(2):222-246.

Romer, P. M. (1986). Increasing returns and long-run growth. The Journal of Political Economy, pages 1002-1037.

Romer, P. M. (1990). Endogenous technological change. Journal of political Economy, pages S71-S102.

UNITED STATES PATENT AND TRADEMARK OFFICE (2012). Setting and Adjusting Patent Fees in accordance with Section 10 of the Leahy-Smith America Invents Act. Regulatory Impact Analysis, U.S. Department of Commerce. 